\title{
IMPLEMENTASI PENDIDIKAN MORAL DI SEKOLAH DASAR
}

\author{
Fathurrohman \\ Program Studi Pendidikan Guru Sekola Dasar UNY \\ Email: fathurrohman@uny.ac.id
}

\begin{abstract}
Abstrak
Isu tentang degradasi moral di Indonesia menjadi catatan penting bagi dunia pendidikan. Sekolah sampai saat ini dianggap ikut bertanggung jawab dalam mencetak generasi penerus bangsa yang lebih baik. Sekolah dasar sebagai institusi menjadi pondasi awal dalam penanaman moral. Bagaimana sekolah dasar memberikan pengalaman belajar kepada siswa. Peran guru dalam proses pembelajaran di SD sangat menentukan masa depan siswa. Pendidikan moral di SD bisa dilakukan dengan berbagai metode baik langsung maupun tidak langsung dengan pembelajaran yang komprehensif. Menciptakan iklim kelas yang baik menjadi faktor penentu keberhasilan pendidikan moral.
\end{abstract}

Kata Kunci: Pendidikan Moral, Sekolah Dasar

\begin{abstract}
The issue of moral degradation in Indonesia is an important problem for the educational world. Until now, schools are considered to be part of the responsibility for creating a better future generation. Primary school as an institution becomes the initial foundation in moral cultivation. How the primary schools provide learning experiences to their students and the role of the teacher in the learning process in elementary school greatly determines the student's future. To achieve those moral education successfulness, the moral education in the elementary schools should be proceed with a comprehensive learning method. Furthermore, a good classroom environment also become the key point for moral education accompishment.
\end{abstract}

Keywords: Moral Education, Elementary School 


\section{PENDAHULUAN}

Pendidikan moral menjadi isu penting akhir-akhir ini di Indonesia. Banyak hal yang melatar belakangi mengapa pendidikan moral harus mendapatkan porsi besar dalam kurikulum Sekolah Dasar di Indonesia. Sekolah Dasar sebagai institusi pendidikan formal mempunyai peran dan tanggung jawab dalam menanamkan pendidikan moral. Sampai sekarang insititusi pendidikan masih dipercaya sebagai medium strategis untuk mengenalkan diri dan menanamkan nilai-nilai moral kepada anak. Namun, tak dapat disangkal, beragam masalah yang masih mendera di lembaga-lembaga pendidikan di Indonesia dalam memfasilitasi anak untuk melatih diri dan berbuat sesuai dengan nilai-nilai moral belum terpenuhi. Sehingga ada ungkapan bahwa lembaga pendidikan dianggap telah gagal dalam membentuk anak bangsa yang memiliki akhlak, moral dan budi pekerti.

Untuk membentuk dan mengarahkan peserta didik pada nilai dan moral baik atau berperilaku baik diperlukan kondisi dan situasi yang benar-benar berada dalam keadaan selaras, tenang, kasih sayang, tanpa perselisihan, dan saling menerima dalam perbedaan. Situasi dan kondisi tersebut diatas dianggap sebagai asumsi bahwa jiwa manusia dalam mengambil keputusan sangat dipengaruhi oleh kondisi jiwa dan lingkungan dimana mereka hidup, bersosialisasi, dan meniru.

Persoalannya adalah bagaimana sebenarnya pendidikan moral itu dapat terinternalisasi dalam diri setiap manusia. Menciptakan sekolah yang dilandasi dengan nilai-nilai moral sebenarnya dapat dimulai dari mana saja sesuai dengan peran masing masing. Salah satu bagian penting yang perlu diperhatikan dalam rangka menuju ke arah pengembangan sekolah yang bermuatan moral adalah melalui penanaman pendidikan moral dalam proses pembelajaran. Implementasi pendidikan moral dalam proses pembelajaran dapat ditempuh dengan menggunakan berbagai metode.

\section{PEMBAHASAN}

\section{Pendidikan moral}

Moral berasal dari bahasa latin mores, dari suku kata mos yang artinya adat istiadat, kelakuan, watak, tabiat, dan akhlak (K. Prent dalam Soenarjati 1989 : 2). Dalam perkembangannya moral diartikan sebagai kebiasaan dalam bertingkah laku yang baik, yang susila. Dari pengertian tersebut dinyatakan bahwa moral adalah berkenaan dengan kesusilaan. Seorang individu dapat dikatakan memiliki moral baik apabila bertingkah laku sesuai dengan kaidah-kaidah moral yang ada. Sebaliknya jika perilaku individu itu tidak sesuai dengan kaidah-kaidah yang ada, maka ia akan dikatakan tidak bermoral.

Moral sebagai prinsip baik buruk yang ada dan melekat dalam diri individu atau seseorang. Walaupun moral itu berada di dalam diri individu, tetapi moral berada dalam suatu sistem yang berwujud aturan ( Ouska dan Whellan dalam Ruminiati, 2007: 32). Moral dan moralitas memiliki perbedaan, karena moral adalah prinsip baik buruk sedangkan moralitas merupakan kualitas pertimbangan baik buruk. Dengan demikian hakikat dan makna moralitas dapat dilihat dari cara individu yang memiliki moral dalam mematuhi maupun menjalankan aturan.

Pendidikan moral merupakan salah satu pendekatan yang dianggap sebagai gerakan utama dalam pendidikan nilai secara komprehensif. Pendidikan moral 
mencakup pengetahuan, sikap, kepercayaan, keterampilan mengatasi konflik, dan perilaku yang baik, jujur, dan penyayang (kemudian dinyatakan dengan istilah "bermoral"). Tujuan utama pendidikan moral adalah menghasilkan individu yang otonom, memahami nilai-nilai moral dan memiliki komitmen untuk bertindak konsisten dengan nilai-nilai tersebut. Pendidikan moral mengandung beberapa komponen yaitu pengetahuan tentang moralitas, penalaran moral, perasaan kasihan dan mementingkan kepentingan orang lain, dan tendensi moral (Darmiyati Zuchdi, 2003:13).

Pendidikan moral sangat penting untuk di terapkan di sekolah dasar dalam rangka menghasilkan anak-anak bermoral. Pestalozzi (Heafford M.R., 1967) menjelaskan kenapa pendidikan moral menjadi sangat mendasar dan penting karena hubungan antara pendidikan intelektual dengan pendidikan moral secara langsung di dasari pada pemahaman bahwa tujuan dari pendidikan adalah untuk meningkatkan kualitas diri dalam memahami sifat alamiah dan kemurnian serta sifat-sifat baik yang ada dalam diri kita. Kemampuan memahami hal tersebut, tidak bisa hanya menggunakan akal saja melainkan dengan hati”.

Lebih lanjut pestalozzy menjelaskan bahwa tujuan pendidikan bukan untuk menanamkan pengetahuan, namun untuk membentangkan kemampuan alami dan mengembangkan kemampuan tersembunyi yang ada dalam setiap orang. Dengan kata lain, pendidik perlu memfokuskan pada anak, dan bukan pada pendidikan itu sendiri.

Pendidikan moral bagi anak SD diharapkan dapat merubah perilaku anak, sehingga peserta didik jika sudah dewasa memiliki tanggung jawab, menghargai sesamanya, dan mampu menghadapi tatangan jaman yang cepat berubah. Disinilah pentingnya nilai-nilai moral yang berfungsi sebagai media transformasi untuk Indonesia lebih baik dengan memiliki keunggulan dan kecerdasan di berbagai bidang; baik kecerdasan emosional, kecerdasan sosial, kecerdasan spiritual, kecerdasan kinestika, kecerdasan logis, musikal, lenguistik, serta kecerdasan spesial (Habibah, 2007: 1).

\section{Metode Pembelajaran}

Pestalozzy menegaskan bahwa metode pembelajaran lebih menekankan pada pentingnya memberikan cinta dan kasih sayang, menciptakan lingkungan kekeluargaan dimana anak dapat tumbuh dan berkembang dengan alami menjadi manusia dengan keseimbangan intelektual, fisik, dan kemampuan teknis, dan dengan pertumbuhan emosional, moral, etika, serta agama. Lebih lanjut Pestalozzi menegaskan bahwa ketika seseorang dididik sedemikian rupa, maka akan ada perbaikan sosial dan terjadi regenerasi yang lebih baik.

Pendidikan moral dapat disampaikan dengan metode langsung atau tidak langsung. Metode langsung mulai dengan penentuan perilaku yang dinilai baik dengan memusatkan perhatian secara langsung pada ajaran tersebut melalui mendiskusikan, mengilustrasikan, dan mengucapkannya. Metode tidak langsung tidak dimulai dengan menentukan perilaku yang diinginkan tetapi dengan menciptakan situasi yang memungkinkan perilaku yang baik dapat dipraktikkan. Keseluruhan pengalaman di sekolah dimanfaatkan untuk mengembangkan perilaku yang baik bagi anak didik (Darmiyati Zuchdi, 2003: 4). 
Sementara Kirschenbaum (1995: 7) menjelaskan bahwa pendidikan nilai dan moral yang dilakukan tidak hanya menggunakan strategi tunggal saja, melainkan harus dilakukan secara komprehensif. Sebagaimana hasil penelitian Rukiyati (2017) yang mengungkapkan bahwa pendidikan moral dirancang secara komprehensif. Strategi tunggal dalam pendidikan moral sudah tidak cocok lagi apalagi yang bernuansa indoktrinasi. Pemberian teladan atau contoh juga kurang efektif diterapkan, karena sulitnya menentukan siapa yang paling tepat untuk dijadikan teladan. Istilah komprehensif yang digunakan dalam pendidikan moral mencakup berbagai aspek. Pertama, pendidikan moral harus komprehensif meliputi semua permasalahan yang berkaitan dengan nilai, mulai dari pilihan nilai-nilai yang bersifat pribadi sampai pertanyaan-pertanyaan mengenai etika secara umum.

Kedua, metode yang digunakan dalam pendidikan moral juga harus komprehensif. Termasuk didalamnya inkulkasi (penanaman) nilai, pemberian teladan, dan penyiapan generasi muda agar dapat mandiri dengan mengajarkan dan memfasilitasi pembuatan keputusan moral secara bertanggungjawab dan keterampilan-keterampilan hidup yang lain. Generasi muda perlu memperoleh penanaman nilai-nilai tradisional dari orang dewasa yang menaruh perhatian kepada mereka, yaitu para anggota keluarga, guru, dan masyarakat. Mereka juga memerlukan teladan dari orang dewasa mengenai integritas kepribadian dan kebahagiaan hidup. Demikian juga mereka perlu memperoleh kesempatan yang mendorong mereka memikirkan dirinya dan mempelajari keterampilan keterampilan untuk mengarahkan kehidupan mereka sendiri.

Ketiga, pendidikan moral hendaknya terjadi dalam keseluruhan proses pendidikan, seperti di kelas, dalam kegiatan ekstra kurikuler, dalam proses bimbingan dan penyuluhan, dalam upacara-upacara pemberian penghargaan, dan dalam semua aspek kehidupan. Contoh-contoh mengenai hal tersebut misalnya tercermin dalam kegiatan yang dilakukan oleh siswa seperti belajar kelompok, penggunaan bahan-bahan bacaan dan topik-topik tulisan mengenai kebaikan. Penggunaan klarifikasi nilai dan dilema moral, pemberian teladan tidak merokok, tidak korup, tidak munafik, dermawan, kejujuran, menyayangi sesama mahluk ciptaan Tuhan, dan lain sebagainya.

Keempat, pendidikan moral hendaknya terjadi melalui kehidupan dalam masyarakat. Orang tua, lembaga keagamaan, aparat penegak hukum, polisi, organisasi kemasyarakatan, semua perlu berpartisipasi dalam pendidikan nilai. Konsistensi semua pihak dalam melaksanakan pendidikan nilai mempengaruhi kualitas moral generasi muda (Kirschenbaum, 1995: 9-10).

Lebih lanjut Kirschenbaum (1995: 15-28) menuliskan bahwa untuk mencapai tujuan tercapainya pendidikan nilai dan moral secara komprehensif ada berbagai cara yang dapat dilakukan. Di Amerika Serikat untuk merealisasikan pendidikan nilai, berbagai metode, program, dan kurikulum telah dikembangkan dalam rangka menolong generasi muda agar dapat mencapai kehidupan yang secara pribadi lebih memuaskan dan secara sosial lebih konstruktif. Dilihat dari substansinya, ada empat pendekatan yang dianggap sebagai gerakan utama dalam pendidikan nilai yang komprehensif yaitu realiasi nilai, pendidikan watak, pendidikan kewarganegaraan, dan pendidikan moral. 
Pestalozzi menekankan bahwa pendidikan harus berpusat pada anak, bukan pada kurikulum ataupun guru. Karena pengetahuan terletak di dalam human being, tujuan pembelajaran adalah untuk menemukan cara untuk membentangkan pengetahuan yang tersembunyi. Pestalozzi mendukung bahwa pengalaman langsung adalah metode yang paling baik. Dia juga mendukung spontanitas dan aktivitas pribadi; hal ini berlawanan dengan metode yang berbasis kurikulum, metode berpusat pada guru yang dulu berlaku.

Guru seharusnya tidak mengajar melalui kata demi kata, misalnya memberikan anak dengan jawaban yang siap dipakai, namun anak harus menemukan jawabannya sendiri. Tidak ada yang lebih baik dari pengalaman sensory. Dengan demikian, Pestalozzi menganjurkan untuk tidak menggunakan buku bagi pendidikan awal, tetapi menganjurkan belajar melalui pengalaman.

Pestalozzy menganjurkan metode induksi, di mana anak pertama belajar mengamati, mengoreksi kesalahan sendiri, menganalisa dan menggambarkan obyek penyelidikan. Anak mulai dengan obyek sederhana dan melakukan observasi sederhana, setelah itu berkembang pada obyek yang lebih kompleks, serta hal-hal abstrak. Hanya setelah mereka benar-benar menguasai tiga hal itu anak mulai diperkenalkan penggunaan buk. Untuk memberikan kesempatan anak memperoleh pengalaman yang banyak tentang alam, Pestalozzi memperluas kurikulum sekolah dasar meliputi geografi, ilmu pengetahuan alam, seni lukis, dan musik.

Sementara pemikiran Lickona tentang pendidikan moral sebenarnya dapat diterapkan dalam suatu proses pembelajaran dengan memasukan ketiga unsur yang saling berkaitan pada topik-topik atau tema yang sedang dipelajari. Melalui tiga kerangka berpikir tersebut hasil pembentukan sikap atau karakter anak dapat dilihat. Masing-masing aspek dalam tiga kerangka pembentukan moral anak yang dikemukakan Lickona memiliki unsur atau aspek-aspek tersendiri. Aspek konsep moral (moral knowing) mencakup kesadaran moral (moral awarness), pengetahuan nilai moral (knowing moralvalue), pandangan ke depan (perspective taking), penalaran moral (moralreasoning), pengambilan keputusan (decision making), dan pengetahuan diri (selfknowledge). Aspek sikap moral (moral feeling) meliputi: kata hati (conscience), rasa percaya diri (self esteem), empati (emphaty), cinta kebaikan (loving thegood), pengendalian diri (self control), dan kerendahan hati (huminity). Aspek perilaku moral (moral behavior) mencakup: kemampuan (compalance), kemauan (will), dan kebiasaan (habbit).

\section{Iklim Kelas}

Iklim kelas adalah kondisi lingkungan kelas dalam hubungannya dengan kegiatan pembelajaran. Iklim kelas merupakan suasana yang ditandai oleh adanya pola interaksi atau komunikasi antara guru-siswa, siswa-guru dan siswa-siswa. Iklim kelas mempunyai pengaruh terhadap atmosfer pembelajaran.

Pestalozzi menganjurkan agar kehidupan kelas seperti kehidupan di keluarga. Atmosfer kelas harus mempunyai suasana loving and caring. Sebagaimana yang terjadi dalam keluarga, harus ada kerjasama, saling mencintai satu sama lain, baik antara guru dengan siswa maupun siswa dengan siswa. Pestalozzy mengembangkan "family classroom" seperti cara seorang ibu membesarkan dia dan saudara perempuannya (Heafford, 1967). 
Pestalozzi mengatakan "There can be no doubt that within the living room of every house hold are united the basic elements of all true human education in its whole range. Dari kalimat tersebut di atas bisa disimpulkan bahwa keluarga adalah komponen esensial dari pendidikan. Keluarga adalah elemen dasar yang utama bagi pendidikan manusia yang sejati. Apabila setiap keluarga menerapkan pendidikan yang baik maka akan memberikan hasil bagi kebaikan masyarakat secara keseluruhan (whole society) dan masyarakat secara luas. Pestalozzi juga menemukan perkembangan baik dari seorang anak yang memperoleh kepercayaan, cinta, dan penghargaan penuh dari ibunya. Seiring berjalannya waktu, sang anak kemudian akan melakukan hal yang sama kepada manusia yang lain. Hal yang sama juga terpantau pada sifat kepatuhan dan disiplin.

Pestalozzi menyarankan guru-guru untuk menciptakan iklim kelas bagaikan kehidupan hangat dalam keluarga. Guru harus selalu memberikan cinta dan kasih sayang, serta kepercayaan kepada anak didik. Pestalozzi mengatakan bahwa apabila tidak ada cinta dan kasih sayang, maka kekuatan intelektual dan fisik dalam diri anak tidak akan berkembang dengan alami. Dia memandang bahwa disiplin yang keras dan kaku, seperti yang banyak diterapkan di berbagai sekolah, hanya akan menjauhkan anak didik dari guru, sehingga menghalangi pertumbuhan dan perkembangan alami dan normal, terutama dalam bidang moral dan etika.

Iklim kelas perlu diorganisasi dengan baik dan humanis sehingga proses belajar mengajar akan terlaksana dengan baik, siswa bisa memperhatikan dan terlibat aktif dalam interaksi kelas, pelajaran bisa dilaksanakan sesuai dengan rencana sehingga tujuan bisa tercapai, kehidupan kelas yang baik akan menyebabkan guru percaya diri dalam mengajar, kelas yang baik adalah kelas yang terbuka menerima apa yang diperoleh dari guru, serta tercipta hubungan antara guru dan siswa yang bersifat positif.

Sosok guru di kelas menjadi sangat penting untuk pendidikan moral anak. Bagaimana guru menghadirkan suasana kelas yang hangat dan menjadi panutan untuk murid-muridnya. (Bern, 2013) menjelaskan secara detail tentang ekologi pengajaran. Buku Bern membahas tentang system ekologi dilihat dari aspek mikrosistem, mesosistem, ekosistem, makrosistem, dan kronosistem dalam kehidupan manusia yang tidak bisa terpisah. berikut ini gambar tentang konsep ekologi manusia: 


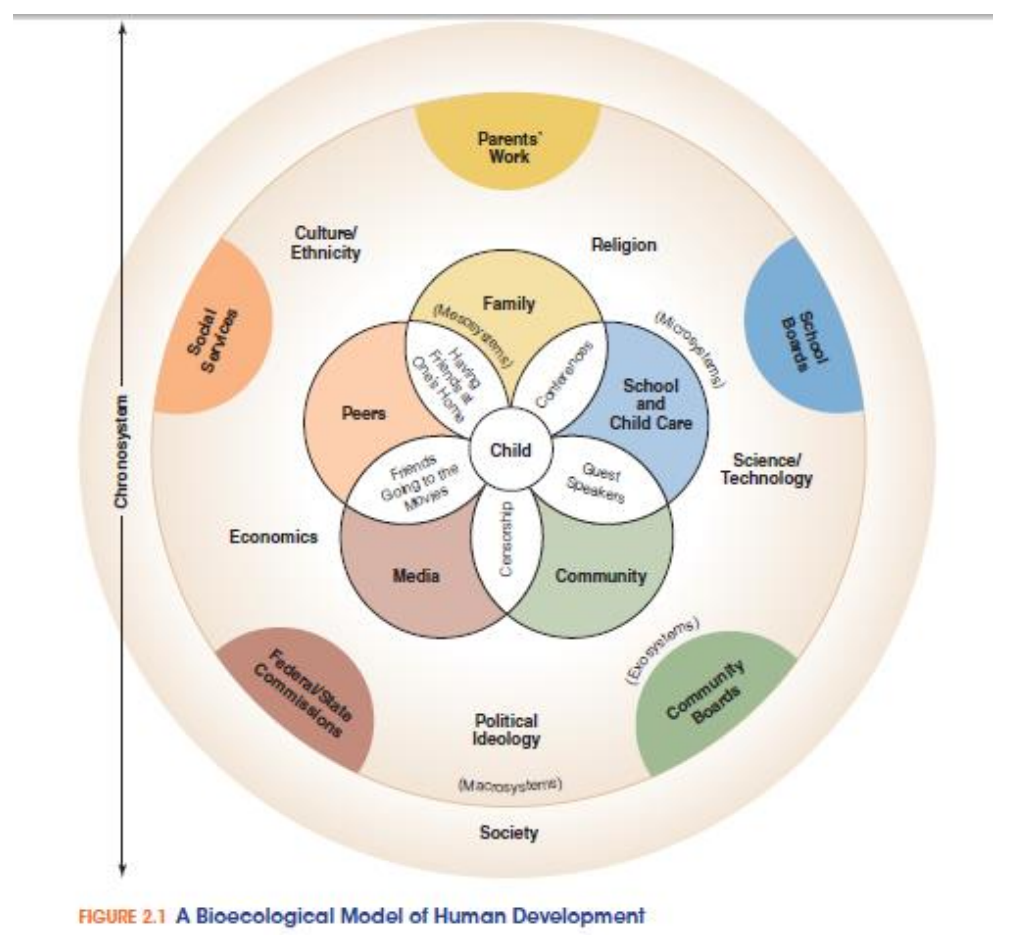

Gambar 1. Model interaksi Manusia (Bern, 2013)

Gambar di atas menjelaskan bahwa interaksi manusia dalam kehidupan tidak bisa terpisah antara organisme dan lingkungannya. Ekologi pengajaran yang dibahas dalam buku Bern berkaitan dengan karakteristik guru dan pembelajaran siswa. Bagaimana karakteristik guru yang dapat mempercepat proses pembelajaran siswa. Guru yang berusaha bekerja sama dengan setiap anak dan memahami dinamika kelompok, cenderung lebih mampu menyediakan lingkungan belajar yang sukses dan bermanfaat. Banyak penelitian yang menemukan bahwa guru yang sukses atau efektif adalah mereka yang hangat, antusias, dan bermurah hati dengan pujian, dan memiliki status tinggi. Selain itu, guru yang sukses adalah mereka yang mampu berkomunikasi dengan baik dan responsif terhadap para siswanya. Sebaliknya, guru yang tidak berhasil atau tidak efektif adalah mereka yang menyendiri (jauh dari siswanya)

Apabila kehidupan ruang kelas bisa baik maka diharapkan tujuan pembelajaran moral bisa dicapai. Faktor guru di kelas memiliki peran yang besar akan terwujudnya perubahan siswa melalui proses belajar yang efektif. Pertumbuhan dan perkembangan moral siswa akan terasah dengan baik dan berdampak kepada penerapan dalam kehidupan bermasyarakat.

\section{KESIMPULAN}

Berdasarkan uraian di atas dapat disimpulkan bahwa implementasi pendidikan moral di SD dilakukan dengan pendidikan berpusat pada anak. Anak didorong untuk memiliki pengalaman langsung dalam pendidikan moral. Pembelajaran secara komprehensif untuk menghasilkan anak yang bermoral menjadi penting dalam perkembangan sekarang ini. Guru harus bisa menciptakan lingkungan belajar di sekolah seperti lingkungan kehidupan keluarga. Kasih sayang dan kepedulian seorang ibu kepada anaknya dalam kehidupan keluarga, juga terjadi 
dalam kehidupan di kelas. Peran orangtua dalam menanamkan pendidikan moral akan berdampak positif terhadap tingkah laku anak di sekolah.

\section{DAFTAR PUSTAKA}

Bern, Roberta M. 2013. Child, Family, School, Community. Socialization and Support. USA

Darmiyati Zuchdi. 2003. Humanisasi Pendidikan (Kumpulan Makalah dan Artikel tentang Pendidikan Nilai). Yogyakarta: Program Pascasarjana UNY.

Dewey,John. Moral Principles in http://www.gutenberg.org/files/25172/25172-h/25172-h.htm

Habibah. 2007. Metode Pengembangan Moral Anak Pra Sekolah. Yogyakarta: FIP UNY. (makalah).

Heafford M.R., 1967, Pestalozzi, Great Britain: Richard Ltd.

Jarolimek, John \& Parker, Walter C. (1993). Social Studies in Elementary Education: Ninth Edition. New York : Macmillan Publishing Company

Joko Wahyono. 2000. Keluarga dan Pendidikan moral anak. http://haluankepri.com/opini-/32547-keluarga-dan-pendidikan-moralanak.html

Kirschenbaum, H. 1995. 100 ways to enhance values and morality in schools and youth settings. Massachusetts: Allyn \& Bacon.

Ruminiati. 2007. Modul Pendidikan Kewarganegaraan SD: Untuk Program S1 PJJ. Jakarta: Dirjen Dikti, Depdiknas R.I.

Rukiyati. 2017. Pendidikan Moral di Sekolah. Jurnal Humanika, Th. XVII, No. 1. September 2017

Soenarjati Muhajir \& Cholisin. (1989). Dasar dan konsep pendidikan pancasila. Yogyakarta: Laboratorium Jurusan PMP dan KN.

Winecoff, H.L. \& Bufford, C. (1985). Toword Improvrd Instruction: A Curriculum Development Handbook for International Scholls. AISA 